\title{
Patent Highlights
}

A snapshot of noteworthy recent developments in the patent literature of relevance to pharmaceutical and medical research and development.

\section{WO/2014/066795}

Heterocyclic compounds for the inhibition of PASK

McCall J, Kelly RC, Romero DL Bioenergix (San Francisco CA, USA)

- casein kinase $\| \cdot$ diabetes mellitus

- mitogen-activated protein kinases

- protein-serine-threonine kinases

The per-arnt-sim domain-containing kinases (PASK) are nutrient-responsive serine/threonine kinases, important for the regulation of glucose metabolism at both the hormonal and cellular level and highly conserved from yeast to man (the inventors refer to PASK as "purine-analog sensitive kinase"). In cultured pancreatic beta-cells, PASK is activated by elevated glucose concentrations and is required for glucose-stimulated transcription of the insulin gene [1], as well as for the regulation of glucagon secretion by glucose; it has been proposed as a target for the treatment of Type 2 diabetes [2]. PASKknockout mice resist diet-induced obesity and have an impaired activation response of AMP-activated protein kinase (AMPK) and the mammalian target of rapamycin (mTOR) pathways. The pyrazolo[1,5-a]pyrimidin7-ones that are claimed here are probably the first well-characterized PASK inhibitors, with $\mathrm{IC}_{50}$ values $<10 \mu \mathrm{M}$ in vitro. Rat pharmacokinetic data are presented for five compounds. Most of these molecules are also shown to inhibit two other kinases, CK2 and PIM1.

Published 1 May 2014

\section{WO/2014/066836}

Pyrazolopyridazines \& methods for treating retinal-degenerative disease \& hearing loss associated with Usher syndrome

Burli RW, Esmieu WRK, Lock CJ et al. Usher III Initiative (Chicago, IL, USA)

- CLRN1 protein, human - genetic diseases, inborn - Usher syndromes

Usher syndrome is characterized by sensorineural deafness and progressive retinitis pigmentosa, and can additionally comprise vestibular abnormalities. This autosomal recessive disease exists in three major clinical subtypes involving more than a dozen genes; type III, the rarest, occurs mainly among people of Ashkenazi Jewhish ancestry and is caused by mutations in CLRNI, the gene coding for the neurosensoriepithelium protein clarin-1 [3], which is an essential component of cone photoreceptors [4] and cochlear hair cells [5]. The predominant mutation, N48K, produces a protein that lacks the $N$-linked glycosylation site, does not reach the cell membrane and is subsequently degraded by the proteasome [6,7]. The pyrazolopyridazines of the invention restore correct trafficking, as is shown by cellular imaging in the HEK293 cell line expressing a hemagglutinin-tagged N48K-clarin. The ultimate mechanism is not disclosed, but this appears to be the first small-molecule Usher syndrome therapy with a clear molecular rationale. See WO/2012/148994, an almost identical document by the same applicant.
Hermann AM Mucke

HM Pharma Consultancy h.mucke@hmpharmacon.com

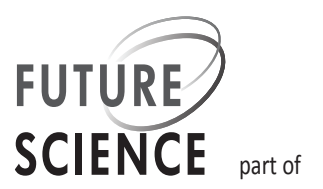


Published 1 May 2014

\section{WO/2014/068542}

Novel targets in multiple myeloma

\& other disorders

Tonon G, Cottini F, Anderson KC

Fondazione Centro San Raffaele

(Milano, Italy); Dana-Farber Cancer Institute

Inc., (Boston, MA, USA).

- multiple myeloma $\cdot$ protein-serine-threonine kinases

- RNA interference • YAP1 (Yes-associated) protein human

While most solid cancers of epithelial origin have inactivating mutations in the p53 tumor suppressor gene, these occur only rarely and late in the development of hematological malignancies; the proto-oncogene $A B L 1$, commonly translocated in leukemias, is of central importance here. The inventors harness the ongoing DNA damage that characterizes multiple myeloma even more than other cancers [8] as a potential Achilles' heel. It is demonstrated that although the ABLl protein is relocalized in the nucleus in multiple myeloma and other hematopoietic disorders as a consequence of widespread DNA damage, myeloma cells are able to survive by either exploiting the low expression levels of the Hippo co-transcriptor factor Yes-associated protein-1 (YAP1) or by genetically inactivating it. YAP1 levels can be restored by inhibiting or inactivating its controlling serine-threonine kinase, STK4 using microRNAs or short hairpin RNAs. This promotes robust apoptosis by increasing the stability of the tumor suppressor p73 and its downstream targets. This is inverse to the situation seen in solid tumors, such as liver cancer [9] or pancreatic cancer [10], where YAP is a key oncogenic driver. For the companion peer review paper see [11].

Published 8 May 2014

WO/2014/075093

Inhibitors of central nervous system vasoactive inhibitory peptide receptor 2 Landry DW, Karayiorgou M, Deng S-X The Trustees of Columbia University in the City of New York (NY, USA).

- gene dosage $\cdot$ receptors $\cdot$ schizophrenia $\cdot$ vasoactive intestinal peptide, type II

Microduplications of chromosomal region 7q36, which lead to increased copy numbers of VIPR2, the gene coding for one of the receptors for vasoactive intestinal peptide, have been implicated in schizophrenia, at least in a subset of patients [12]. Building on the single peptidomimetic small-molecule VIPR2 antagonist that screening of 1.67 million compounds had previously identified [13], the inventors have engineered molecules with better brain penetration. One of the most active molecules is $(2 R, 4 S)$-2-benzyl-4-hydroxy-N-[(1S,2R)-2-hydroxy2,3-dihydro-1H-inden-1-yl]-4-[4-(trifluoromethyl) benzenesulfonamido]butanamide. In conjunction with Columbia University's application WO/2012/094681 claiming methods for determining VIPR2 copy number variations as a means to diagnose schizophrenia, the present application appears to be part of an effort towards an integrated pharmacogenetic approach to schizophrenia. At least eight other genes (NRXN1, CHRNA7, BCL9, CYFIP1, GJA8, NDE1, SNAP29 and GJA5) have also been implicated in copy number variations that confer susceptibility to schizophrenia [14].

Published 15 May 2014

\section{WO/2014/077715}

1,3-dihydroimidazole-2-thione derivatives for use in the treatment of pulmonary arterial hypertension \& lung injury Soares da Silva PMVA, Bonifácio MJM BIAL - Portela \& Ca., SA, São Mamede do Coronado (Portugal).

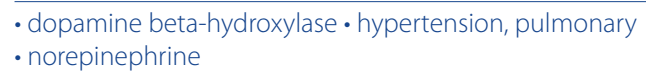

Pulmonary arterial hypertension is still incurable, although endothelin receptor antagonists, phosphodiesterase inhibitors, prostacyclins and soluble guanylate cyclase stimulators have made it a manageable condition. The present application implies a new molecular target, although it does not explicitly state so: the application remains silent concerning the mechanism of $(R)-5$-(2-(benzylamino)ethyl)-1-(6,8difluorochroman-3-yl)-1H-imidazole-2(3H)-thione, one of the two most preferred compounds, which at $30 \mathrm{mg} / \mathrm{kg} /$ day was more effective in the rat model of monocrotaline-induced pulmonary hypertension than the prototypical dual endothelin receptor antagonist, bosentan (100 or $300 \mathrm{mg} / \mathrm{kg} /$ day) and synergized with it. Only Bial's referenced patents (WO/2004/033447 and $\mathrm{WO} / 2008 / 136695)$ reveal that these are inhibitors of dopamine $\beta$-hydroxylase, the monoxygenase that converts dopamine to norepinephrine. Indeed the abovementioned agent is etamicastat, currently in clinical development for the treatment of (classical, left-heart) hypertension and heart failure [15]. The extension to pulmonary arterial hypertension is anything but trivial; the two conditions have little in common in terms of etiology and therapy. Dopamine $\beta$-hydroxylase has mostly been implicated in 
neurological and psychiatric disorders, including migraine [16] and addiction [17].

Published 22 May 2014

\section{WO/2014/079504}

Policyclic ligands of 5-HT7 receptor

\& use thereof.

Leopoldo M, Lacivita E, Colabufo NA et al. Biofordrug srl, (Bari Italy).

- antidepressive agents $\cdot$ serotonin 7 receptor

The serotonin 5-HT7 receptor has been known for 20 years, but it never became an independent drug target although newer atypical antipsychotics, such as amisulpride and lurasidone, are known to bind to it. Pharmacological blockade or genetic inactivation causes antidepressant-like behavior in rodent models of depression; agonists can have neuroprotective effects, modulate neuronal plasticity, enhance morphine-induced antinociception and alleviate hyperalgesia after nerve injuries. In behavioral memory tasks 5-HT7 receptor agonists, as well as antagonists have amnesic and antiamnesic effects [18,19]. The most potent 5-HT7 ligands reported to date are not sufficiently metabolically stable to be developed as drugs. The compounds of the present invention are more drug-like when incubated with rat liver S9 fractions, suggesting better pharmacokinetic properties, and possess optimal lipophilicity $(\log P 2.0-3.5)$ for both in vivo use and for the development as tracers for brain PET imaging. On 5-HT7 receptors recombinantly expressed in HEK293-EBNA cells some exhibit $\mathrm{K}_{\mathrm{i}}$ values down to the low nanomolar range, for example, N-methyl-6-[4-[2-(4-methoxyphenyl)phenyl]$\mathrm{N}$-(2-pyridyl)-1-piperazinehexanamide. As is the case with all 5-HT7 ligands reported so far, these also bind to 5-HT1A receptors; both receptors are highly coexpressed in brain regions implicated in depression, and form homo- and heterodimers both in vitro and in vivo.

Published 30 May 2014

\section{WO/2014/083529}

Heterocyclic compounds as inhibitors of the sodium iodide symporter

Amboise $Y$, Lacotte $P$

Commissariat à l'Énergie Atomique et aux Énergies alternatives (Paris, France).

- symporters $\bullet$ thyroid gland $\cdot$ thyroid neoplasms

Iodide capture by the thyroid gland is mediated by the sodium iodide symporter (NIS), a thyrocyte glycoprotein from the solute carrier family with no less than 13 transmembrane domains. This is essential for the biosynthesis of the thyroid hormones, triiodothyronine (T3) and its precursor, thyroxine (T4) [21]. Decreased NIS expression is found with Hashimoto's thyroiditis [22] and in differentiated but aggressive papillary carcinomas of the thyroid [23]. On the other hand, in case of inadvertent exposure to radioiodine after a nuclear accident, targeted blockade of the NIS would be much more elegant (and, presumably, safer for the thyroid) than administering large amounts of 'cold' potassium iodide - which is the current measure of preparedness for such cases. Tetrahydrocarbolines [24] and 3,4-dihydropyrimidin-2 $(1 \mathrm{H})$-ones [25] have been reported as NIS inhibitors with nanomolar $\mathrm{IC}_{50}$ values. Claimed here is another class, 1-(phenyl)-1,3,4,9tetrahydropyrano[3,4-b]indoles, some of which also have low nanomolar $\mathrm{IC}_{50}$ values. Treatment of cancers (not only of the thyroid; the NIS is also expressed in other malignancies [26]) and functional imaging are other potential applications.

Published 5 June 2014

\section{WO/2014/084859}

Molecules \& methods for modulating

TMEM16A activities

Gaither LA, Rothwell CJ

Novartis AG (Basel, Switzerland).

- ANO1 protein, human $\cdot$ chloride channels $\cdot$ gastrointestinal

stromal tumors $\cdot$ head and neck neoplasms

The transmembrane protein 16a (TMEM16A; anoctamin-1) is encoded on the long arm of chromosome 11 (region 11q13) and is highly overexpressed in several tumors, especially gastrointestinal stromal tumor and head and neck cancers [27]. Before it was shown to be a component of a calcium-activated chloride channel $[28,29]$ it had been known as the cancer marker, DOG1 [30]. The invention provides antibodies and engineered proteins that specifically bind to the extracellular domain 2 or 3 of TMEM16A (minimum binding domains KLIRYLKLKQ and RYKDYREPPWS), and internalize upon binding. According to the claims this might open avenues for the therapy of cancers with the 11 q13 amplification, especially to those that are resistant to kinase inhibitors or other monoclonal antibodies. However, the known roles of TMEM16A would suggest that the utility of these ligands could extend to kidney conditions [31] and cystic fibrosis [32].

Published 5 June 2014

WO/2014/086790

Cyclopropylamine derivatives useful as 
inhibitors of histone demethylases KDMA1. Varasi $\mathrm{M}$, Vianello $\mathrm{P}$, Thaler $\mathrm{F}$ et al. Istituto Europeo di Oncologia srl, (Milano, Italy).

- epigenomics • histone demethylases • leukemia promyelocytic acute

The discovery of an increasing number of histone lysine demethylases has highlighted the dynamic nature of the regulation of histone methylation, a key chromatin modification that is involved in eukaryotic genome and gene regulation. These demethylases represent attractive targets for epigenetic drugs, especially for oncology. KDM1A (also known as lysine-specific demethylase 1, LSD1) specifically removes the methyl groups from both mono- and di-methyl lysine- 4 of histone $\mathrm{H} 3$ [33], creating a well-characterized gene activation mark. Interestingly, the old antidepressant trancylpromine (trans-2-phenylcyclopropylamine) is a strong KDM1A inhibitor; the mechanism (formation of a covalent adduct with the enzyme's flavin-adenine dinucleotide essential cofactor) is the same as with its longknown target monoamine oxidase $\mathrm{B}$, but the adduct with KDM1A is a different one [34]. This triggered the development of tranylcypromine analogs, of which the 2-aryl or heteroaryl-(1-substituted) cyclopropylamines that are claimed here are the most recent ones. In an acute promyelocytic leukemia mouse model, $\mathrm{N}$-(4trans-2-amino-2-ethyl-cyclopropylphenyl)-4-phenylbenzamide administered orally at $30 \mathrm{mg} / \mathrm{kg}$ achieved a reduction of the spleen weight of approximately 50\% compared with mice treated with the vehicle. KDMA1 has also been identified as a target in medulloblastoma, a leading cause of childhood cancer-related deaths [35].

Published 12 June 2014

\section{WO/2014/090265 \\ MSI-specific frameshift peptides (FSP) for prevention \& treatment of cancer Kloor M, Reuschenbach M, von Knebel- Döberitz M \\ Ruprecht-Karls-Universität (Heidelberg, Germany).}

- cancer vaccines • colorectal neoplasms • hereditary nonpolyposis - microsatellite instability

Microsatellite instability (MSI) that results from defects in the DNA mismatch repair system is one of the two major pathways of genome instability through which cancers form and evolve. MSI is encountered in a subset of approximately $15 \%$ of colorectal cancers, which are characterized by a high immunogenicity that results from the generation of numerous but predictable frameshift peptides (FSP), a direct result of mismatch repair deficiency [36,37]. However, the clonal immune response is usually inadequate for tumor eradication. The invention provides a vaccine containing a FSP derived from four genes known to be subject to high-grade MSI: TAF1B (a component of the basal transcription machinery for RNA polymerase I), ASTE1/HT001 (asteroid homolog 1), AIM2 (Absent in Melanoma 2) or TGFBR2 (transforming growth factor $\beta$-receptor II). Such a vaccine would mostly target patients with Lynch syndrome, one of the most common cancer susceptibility syndromes, which is caused by $3^{\prime}$-end deletions of the EPCAM epithelial cell adhesion molecule gene and results in a high risk for developing nonpolyposis colorectal cancer and endometrial cancer. Targeted genetic screening and counseling for Lynch syndrome is increasingly established and can be developed to high standards [38].

\section{Published 19 June 2014}

\section{WO/2014/096437}

Alternative oxidase (AOX) prevents smoking-associated lung damage Szibor M, Braun T, Voswinckel R et al. Max-Planck-Gesellschaft zur Förderung der Wissenschaften eV (München Germany); University of Tampere (Finland).

- alternative oxidase $\cdot$ smoke inhalation injury $\cdot$ smoking

Tobacco smoke contains dozens of major carcinogens and many toxins, but its most immediate effect on lung tissue is exerted by carbon monoxide, which inactivates cytochrome c oxidase, compromising oxidative phosphorylation [39] and incapacitating the bronchial cilia from expelling the particulate contents of cigarette smoke. The invention intends to alleviate this by administering alternative oxidase (AOX), an additional mitochondrial enzyme that parallelizes cytochrome $\mathrm{C}$ in plants and invertebrates and can bypass inhibition of the respiratory chain (this is Otto Warburg's 'cyanide-resistant respiration' and its absence in vertebrates is the reason why cyanogenic compounds are among the most frequently encountered poisons in nature to resist animal predators). Functional AOX from the marine invertebrate Ciona intestinalis can be expressed in cultured human embryonic kidney cells and fibroblasts, where it is efficiently targeted to mitochondria by the cell's own protein-sorting machinery [40]. When mouse 3T3 fibroblasts transfected with a lentivirus vector expressing AOX from a constitutive promoter were exposed to medium containing $2.5 \%$ cigarette smoke extract, their growth was almost uninhibited for two days and showed only minimal evidence of nuclear DNA damage and apoptosis. A similar protective effect was seen 
against damage from standardized diesel exhaust particles. The in vivo experiments with transgenic mice showed protection against cigarette smoke and also an attenuated increase of pulmonary arterial pressure when exposed to hypoxia, suggesting potential utility of an AOX gene therapy in pulmonary arterial hypertension and altitude sickness. Note, work from a different group demonstrating prolonged protection of AOX-expressing mice against a lethal concentration of gaseous cyanide [41]. Also see WO/2013/102764 from the University of Sussex (UK) for the production of recombinant AOX, and US Patent No. 7,572,616 for its other medical uses.

Published June 26, 2014

\section{WO/2014/096498}

Tungstate salts as anti-platelet agents

Díaz Ricart MI, Pino Ferrer M, Escolar

Albaladejo G et al.

Universitat de Barcelona (Spain);

Hospital Clinic de Barcelona (Spain)

Institut $d^{\prime}$ Investigacions Biomèdiques August

Pi I Sunyer (Barcelona, Spain);

Centro de Investigación Biomédica en red (CIBER), ES/ES (Madrid, Spain).

- platelet activation $\cdot$ sodium tungstate $(\mathrm{VI})$

Proposed pharmaceutical applications for tungsten are rare. The few that exist, such as those in

\section{References}

1 Hao HX, Rutter J. The role of PAS kinase in regulating energy metabolism. IUBMB Life 60 (4), 204-209 (2008).

2 da Silva Xavier G, Farhan H, Kim H et al. Per-arnt-sim (PAS) domain-containing protein kinase is downregulated in human islets in Type 2 diabetes and regulates glucagon secretion. Diabetologia 54(4), 819-827 (2011).

3 Herrera W, Aleman TS, Cideciyan AV et al. Retinal disease in Usher syndrome III caused by mutations in the clarin-1 gene. Invest. Ophthalmol. Vis. Sci.49(6), 2651- 2660 (2008).

4 Ratnam K, Västinsalo H, Roorda A et al. Cone structure in patients with usher syndrome type III and mutations in the Clarin 1 gene. JAMA Ophthalmol. 131(1), 67-74 (2013).

5 Geng R, Melki S, Chen DH et al. The mechanosensory structure of the hair cell requires clarin-1, a protein encoded by Usher syndrome III causative gene.J. Neurosci. 32(28), 9485-9498 (2012).

6 Tian G, Zhou Y, Hajkova D et al. Clarin-1, encoded by the Usher syndrome III causative gene, forms a membranous microdomain: possible role of clarin-1 in organizing the actin cytoskeleton. J. Biol. Chem. 284(28), 18980-18993 (2009).

7 Isosomppi J, Västinsalo H, Geller SF et al. Disease-causing mutations in the CLRN1 gene alter normal CLRN1 protein
WO/2007/014970 for Alzheimer's disease (where phoshorylation of tau protein is said to be inhibited [42]) and schizophrenia, and EP-755681 for diabetes (a clinical trial in obesity had negative results [43]), all claim simple tungsten (VI) salts. Most of the published work comes from Spain, like the present one, which claims sodium tungstate as an antiplatelet agent. Results are shown for in vitro coagulation of human blood and platelet preparations $(200 \mu \mathrm{M}$ sodium tungstate) and for mice receiving sodium tungstate at $2 \mathrm{~g} / \mathrm{l}$ in drinking water for 1 week. Under flow conditions in vitro there was also a decrease in the interaction of platelets with collagen and a reduction in clot size. There does not seem to be anything in the peer review literature suggesting an effect of tungstates on coagulation, and the data in this patent document do not allow to deduce a putative mechanism.

\section{Published 26 June 2014}

\section{Financial \& competing interests disclosure}

The author has no relevant affiliations or financial involvement with any organization or entity with a financial interest in or financial conflict with the subject matter or materials discussed in the manuscript. This includes employment, consultancies, honoraria, stock ownership or options, expert testimony, grants or patents received or pending, or royalties.

No writing assistance was utilized in the production of this manuscript.

trafficking to the plasma membrane. Mol. Vis. 15, 1806-1818 (2009).

8 Neri P, Bahlis NJ. Genomic instability in multiple myeloma: mechanisms and therapeutic implications. Expert Opin. Biol. Ther. 13 (Suppl.1), S69-S82 (2013).

9 Liu AM, Xu MZ, Chen J et al. Targeting YAP and Hippo signaling pathway in liver cancer. Expert Opin. Ther. Targets 14(8), 855-868 (2010).

10 Kapoor A, Yao W, Ying H et al. Yap1 activation enables bypass of oncogenic kras addiction in pancreatic cancer. Cell 158(1), 185-197 (2014).

11 Cottini F, Hideshima T, Xu C et al. et al. Rescue of Hippo coactivator YAP1 triggers DNA damage-induced apoptosis in hematological cancers. Nat. Med. 20(6), 599-606 (2014).

12 Vacic V, McCarthy S, Malhotra D et al. et al. Duplications of the neuropeptide receptor gene VIPR2 confer significant risk for schizophrenia. Nature 471(7339), 499-503 (2011).

13 Chu A, Caldwell JS, Chen YA. Identification and characterization of a small molecule antagonist of human VPAC(2) receptor. Mol. Pharmacol. 77(1), 95-101 (2010).

14 Luo X, Huang L, Han L et al. Systematic prioritization and integrative analysis of copy number variations in schizophrenia reveal key schizophrenia susceptibility genes. Schizophr. Bull. (2014)doi:10.1093/schbul/ sbu045 (Epub ahead of print). 
15 Almeida L, Nunes T, Costa R et al. Etamicastat, a novel dopamine $\beta$-hydroxylase inhibitor: tolerability, pharmacokinetics, and pharmacodynamics in patients with hypertension. Clin. Ther. 35(12), 1983-1996 (2013).

16 Fernandez F, Colson N, Quinlan S et al. Association between migraine and a functional polymorphism at the dopamine beta-hydroxylase locus. Neurogenetics 10 (3), 199-208 (2009).

17 Schroeder JP, Epps SA, Grice TW, Weinshenker D. The selective dopamine $\beta$-hydroxylase inhibitor nepicastat attenuates multiple aspects of cocaine-seeking behavior. Neuropsychopharmacology38(6), 1032-1038 (2013).

18 Hedlund PB. The 5-HT7 receptor and disorders of the nervous system: an overview. Psychopharmacology (Berl.) 206(3), 345-354 (2009).

19 Di Pilato P, Niso M, Adriani W et al. Selective agonists for serotonin 7 (5-HT7) receptor and their applications in preclinical models: an overview. Rev. Neurosci. 25(3), 401-415 (2014).

20 Naumenko VS, Popova NK, Lacivita E et al. Interplay between serotonin 5-HT1A and 5-HT7 receptors in depressive disorders. CNS Neurosci. Ther. 20(7), 582-590 (2014).

21 Dohán O, De la Vieja A, Paroder V et al. The sodium/iodide Symporter (NIS): characterization, regulation, and medical significance. Endocr. Rev. 24(1), 48-77 (2003).

22 Popławska-Kita A, Telejko B, Siewko K et al. Decreased expression of thyroglobulin and sodium iodide symporter genes in Hashimoto's thyroiditis. Int. J. Endocrinol. 2014, 690704 (2014)

23 Ward LS, Santarosa PL, Granja F et al. Low expression of sodium iodide symporter identifies aggressive thyroid tumors. Cancer Lett. 200 (1), 85-91 (2003).

24 Lecat-Guillet N, Merer G, Lopez R et al. Small-molecule inhibitors of sodium iodide symporter function. Chembiochem 9(6), 889-895 (2008).

25 Lacotte P, Puente C, Ambroise Y. Synthesis and evaluation of 3,4-dihydropyrimidin-2 $(1 \mathrm{H})$-ones as sodium iodide symporter inhibitors. ChemMedChem. 8(1), 104-111 (2013).

26 Micali S, Bulotta S, Puppin C et al. Sodium iodide symporter (NIS) in extrathyroidal malignancies: focus on breast and urological cancer. BMC Cancer 14(1), 303 (2014).

27 Wanitchakool P, Wolf L, Koehl GE et al. Role of anoctamins in cancer and apoptosis. Philos. Trans. R. Soc. Lond. B Biol. Sci. 369(1638), 20130096 (2014).

28 Caputo A, Caci E, Ferrera L et al. TMEM16A, a membrane protein associated with calcium-dependent chloride channel activity. Science 322(5901), 590-594 (2008).

29 Yang YD, Cho H, Koo JY et al. TMEM16A confers receptor-activated calcium-dependent chloride conductance. Nature 455(7217), 1210-1215 (2008).

30 Berglund E, Akcakaya P, Berglund D et al. Functional role of the $\mathrm{Ca}^{2+}$-activated $\mathrm{Cl}^{-}$channel DOG1/TMEM16A in gastrointestinal stromal tumor cells. Exp. Cell Res. 326(2), 315-325 (2014).

31 Svenningsen P, Nielsen MR, Marcussen N et al. TMEM16A is a $\mathrm{Ca}^{2+}$-activated $\mathrm{Cl}^{-}$channel expressed in the renal collecting duct. Acta Physiol. (Oxf.) 212(2), 166-174 (2014).

32 Sondo E, Caci E, Galietta LJ. The TMEM16A chloride channel as an alternative therapeutic target in cystic fibrosis. Int. J. Biochem. Cell Biol. 52, 73-76 (2014).

33 Forneris F, Binda C, Battaglioli E, Mattevi A. LSD1: oxidative chemistry for multifaceted functions in chromatin regulation. Trends Biochem. Sci. 33(4), 181-189 (2008).

34 Yang M, Culhane JC, Szewczuk LM et al. Structural basis for the inhibition of the LSD1 histone demethylase by the antidepressant trans-2-phenylcyclopropylamine. Biochemistry 46(27), 8058-8065 (2007).

35 Pajtler KW, Weingarten C, Thor T et al. The KDM1A histone demethylase is a promising new target for the epigenetic therapy of medulloblastoma. Acta Neuropathol. Commun. 1(1), 19 (2013).

36 Tougeron D, Fauquembergue E, Rouquette A et al. Tumor-infiltrating lymphocytes in colorectal cancers with microsatellite instability are correlated with the number and spectrum of frameshift mutations. Mod. Pathol. 22(9), 1186-1195 (2009).

37 Schwitalle Y, Linnebacher M, Ripberger E et al. Immunogenic peptides generated by frameshift mutations in DNA mismatch repair-deficient cancer cells. Cancer Immun. 4, 14 (2004).

38 Boyle TA, Bridge JA, Sabatini LM et al. Summary of microsatellite instability test results from laboratories participating in proficiency surveys: proficiency survey results from 2005 to 2012. Arch. Pathol. Lab. Med. 138(3), 363-370 (2014).

39 Queiroga CS, Almeida AS, Vieira HL. Carbon monoxide targeting mitochondria. Biochem. Res. Int. 2012, 749845 (2012)

40 Dassa EP, Dufour E, Gonçalves S et al. Expression of the alternative oxidase complements cytochrome c oxidase deficiency in human cells. EMBO Mol. Med. 1(1), 30-36 (2009).

41 El-Khoury R, Dufour E, Rak M et al. Alternative oxidase expression in the mouse enables bypassing cytochrome c oxidase blockade and limits mitochondrial ROS overproduction. PLoS Genet. 9(1), e1003182 (2013).

42 Gómez-Ramos A, Domínguez J, Zafra D et al. Sodium tungstate decreases the phosphorylation of tau through GSK3 inactivation. J. Neurosci. Res. 83(2), 264-273 (2006).

43 Hanzu F, Gomis R, Coves MJ. Proof-of-concept trial on the efficacy of sodium tungstate in human obesity. Diabetes Obes. Metab. 12(11), 1013-1018 (2010). 